\title{
A Liberdade COMO SÍNTESE DE VALORES: Dí́lOGOS ENTRE REPUBLICANISMO E TEORIA CRÍTICA
}

\author{
[FREEDOM AS SYTHESE OF VALUES: DIAOGUES BETWEEN CRITICAL THEORY AND \\ REPUBLICANISM]
}

Joedson de Santana Oliveira *

\begin{abstract}
Resumo: O trabalho tem por objetivo mostrar que a reconstrução normativa da liberdade realizada por Axel Honneth no seio da teoria crítica e por Philip Pettit no âmbito da teoria republicana concorre para objetivos comuns, qual seja a superação da dicotomia liberdade positiva (reflexiva) versus liberdade negativa. Como resultado, temos, em ambos os autores, uma concepção de liberdade que mantem os valores modernos da autonomia do sujeito sem, contudo, limitá-la a este aspecto autorreferente. Irei sugerir que a liberdade como não dominação de Pettit ganharia mais densidade sociológica se fosse mediada pela categoria reconhecimento tal qual aparece na teoria crítica de Honneth.
\end{abstract}

Palavras-chave: Republicanismo. Teoria Crítica. Reconhecimento. Não Dominação.
ABSTRACT: This paper aims show that the normative reconstruction of the freedom performed by Axel Honneth in critical theory and Philip Pettit within the Republican theory tend towards common goals, namely the overcoming of positive freedom dichotomy (reflective) versus negative freedom. As a result, we have, in both authors, a conception of freedom that keeps the modern values of individual autonomy, but without limiting it to this self-referential aspect. I will propose that freedom as non-domination Pettit gain more sociological density if it were mediated by category recognition Honneth.

KeYwords: Republicanism. Critical Theory. Recognition. Non-domination.

\section{I.CONSIDERAÇÕES INICIAIS}

$\mathrm{m}$ seu famoso ensaio Ética a Nicômaco Aristóteles se pergunta qual o bem
mais importante que alguém pode aspirar e chega à ideia Eudaimonia (do

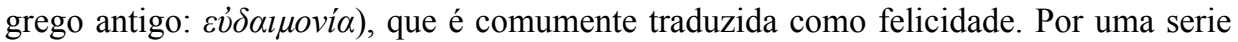
de razões a busca da Eudaimonia foi abandonada pela tradição filosófica que, a parir da modernidade, passou a colocar valores como a liberdade como síntese de todos os valores a serem perscrutados tanto num nível individual como num plano coletivo.

* Professor do Instituto Federal de Educação, Ciência e Tecnologia do Piauí, IFPI. Doutorando em filosofia na Pontifícia Universidade Católica do Rio Grande do Sul, PUCRS. Nota: Este artigo é parte da tese de doutorado que está sendo realizado na Pontificia Universidade Católica do Rio Grande do Sul, PUCRS, e uma versão parcial do mesmo foi apresentado no II Colóquio Interfaces Críticas: teoria crítica, política, direito, realizado nos dias 8 e 9 de setembro na Universidade Federal da Paraíba, UFPB.m@ilto: joedson11@hotmail.com 
Philip Pettit, filósofo defensor de uma tradição republicana e Axel Honneth, vinculado à Teoria Crítica são dois exemplos que corroboram com essa tese da liberdade como síntese de valores. No trabalho mais recente de Honneth, Direito da liberdade (2016), o autor se propõe fazer uma reconstrução normativa da liberdade, cujos fundamentos coincidem com a liberdade republicana formulada por Pettit. Embora os dois autores tenham heurística distintas, Honneth tem como inspiração a filosofia do direito de Hegel, ao passo que Pettit tem como propósito fazer uma reconstrução do republicanismo que remonta a Cícero e Maquiavel. Em comum, os autores compartilham a superação da dicotomia liberdade positiva versus liberdade negativa; corroborando com a tese de que a efetivação da liberdade subjetiva só é possível mediante a objetividade das instituições sociais; a ideia de que as pretensões de autonomia e autorrealização só fazem sentido nas relações sociais intersubjetivas, mediada pelo reconhecimento recíproco. O reconhecimento como categoria mediadora, contudo, é um elemento ausente na teoria republicana de Pettit. A ideia que pretendo desenvolver, portanto, parte do insight de que a liberdade é uma realização sóciopolítica a qual depende de um conjunto de relações intersubjetivas de reconhecimento reciproco. Isso representa um avanço diante do paradigma liberal que fica no aspecto autorreferencial da liberdade, reduzindo-a a proteção das liberdades básicas dos sujeitos de direitos. Não que os postulados liberais de sujeitos que na sua pluralidade de concepções de bem reivindicam proteção para usufruir da vida na sua dimensão privada estejam totalmente equivocados, tais postulados são legítimos, mas tem se demonstrado insuficientes e deficitários para se pensar uma teoria da justiça com vista a resolver os grandes desafios da teoria social, cuja malha grossa da liberdade negativa não consegue capturar, tais como, o fenômeno da dominação, a alienação e as injustiças nas suas diversas nuances que permeiam as relações humanas em seus diversos aspectos: injustiças oriundas das relações étnicas, de gênero, raça, bem como resultando das exclusões materiais implicadas das relações de trabalho injustas.

Assim, a reconstrução sócio-normativa da liberdade feita por Honneth bem como seu equivalente na teoria republicana de Pettit, visam apresentar uma alternativa aos dilemas ético-políticos que as sociedades ostentam sem uma saída plausível e cujo paradigma liberal vigente tem demonstrado pouco poder de convencimento em seu diagnóstico. Para fins didáticos, abordarei essas questões em duas seções. Na primeira seção eu tratarei da liberdade sob a perspectiva republicana, sobretudo com referência ao trabalho de Philip Pettit que defende a tese de um "holismo individualista" como base para sua teoria da não dominação. Ressaltarei que a abordagem que Pettit faz da dominação tem suas limitações, em parte, por ficar em discussões puramente analíticas sobre o fenômeno da dominação, carecendo, portando, de mais densidade sociológica. $\mathrm{Na}$ segunda seção, irei apresentar a proposta de Honneth, de inspiração hegeliana que, similar ao trabalho de Pettit, esboçará uma teoria da liberdade, realçando tanto o seu aspecto individual como suas expressões institucionais. Crítico da concepção liberal que reduz a liberdade a sua dimensão individual autorreferente, Honneth é enfático ao afirmar que "a liberdade dos indivíduos ao fim e ao cabo só se efetiva lá onde eles podem participar de instituições cujas práticas normativas asseguram uma relação de reconhecimento mútuo" (p. 89). 


\section{II.A ABORDAGEM REPUBLICANA DA DOMINAÇÃO E SUAS LIMITAÇÕES}

A abordagem que Pettit faz da liberdade como não dominação visa inicialmente refutar uma tese de Isaiah Berlin que, num ensaio intitulado Dois conceitos de liberdade (2002), afirma que historicamente houve apenas duas maneiras de pensar a liberdade: a liberdade positiva e a liberdade negativa que correspondia à liberdade dos antigos e a liberdade dos modernos, respectivamente, tal qual Benjamin Constant já intuíra. Segundo Pettit, ao limitar a liberdade nessas duas possiblidades, Berlin limita e empobrece o debate sobre o tema. Por isso, o autor propõe uma terceira via a dicotomia criada por Berlin se baseando no movimento de atualização do republicanismo cuja inspiração é o filosofo florentino, Nicolau Maquiavel.

As leituras que conferem a Maquiavel o status de republicano são muito diversificadas, mas um dos aspectos centrais, presente em boa parte dos teóricos republicanos, é a ideia de não dominação. Porém, se é certo que a dominação é um conceito central para a tradição republicana, não parece muito claro e evidente o que constitui realmente a dominação para os teóricos republicanos. O próprio movimento de retorno ao republicanismo tem muitas variáveis e é possível encontrar diferentes abordagens da dominação e diferentes deduções desse conceito para a teoria política. John McCormick, professor da Universidade de Chicago, faz uma leitura de Maquiavel bem mais radical que Pettit e tem duras críticas a Pettit e aos demais leitores de Maquiavel associados à Escola de Cambridge. Segundo McCormick, Pettit capta o que há de mais elitista e conservador na sua apropriação de Maquiavel, alterando e avançando muito pouco em sua crítica ao liberalismo.

Antes de tratar da dominação, vale ressaltar o que não corresponde à concepção republicana da dominação. Frank Lovet entrou nesse terreno e fez uma abordagem polissêmica da dominação, demonstrado as distintas acepções que a terminologia pode ganhar e que não se confundem com a dominação no sentido que o republicanismo a aborda. Na famosa dialética do senhor e do escravo, presente na Fenomenologia do Espírito de Hegel, temos uma genérica referência a uma relação de dominação, mas que pouco diz sobre a dominação no geral. De acordo com Hegel a dominação é autodestrutiva para o próprio senhor que assume uma posição dominante numa dada relação. Isto ocorre porque Hegel parte do pressuposto de que uma pessoa só pode alcançar plena autoconsciência de si como ser autônomo e independente através do reconhecimento de outros. Dada a justeza desse argumento, podermos deduzir que, ao sujeitar outrem à dominação, o reconhecimento obtido oriundo de um objeto de dominação acaba por se revelar completamente inútil. E ao mesmo tempo, ao colocar o objeto dominado para trabalhar para satisfazer seus desejos, o agente dominante passa para terceiros a oportunidade para realizar sua própria autoconsciência como ser autônomo e independente, capaz de transformar a natureza de acordo com seus próprios interesses (Cf. Lovett, 2010, p. 137). Estas considerações de Hegel sobre o problema da dominação, embora sejam relevantes, acabam por ser residuais e não atingem o núcleo do problema que reside muito mais na parte dominada que na parte dominante.

A concepção de dominação de Max Weber, bastante difundida, aparece nos seguintes termos: "dominação (Herrchaft) é a probabilidade que um comando com dado conteúdo específico seja obedecido por um determinado grupo de pessoas" (1978, p.54) De acordo com Weber "uma organização governante existe até o ponto em que 
seus membros sejam sujeitos a dominação por parte da ordem estabelecida" (p.54). Portanto, de acordo com Weber, é teoricamente concebível que a sociedade seja permeada de relações de dominação que, na visão do autor, vão além das estruturas administrativas do estado, podendo ser exercida por um chefe de família dentre outros agentes. As criticas que recaem sobre esta concepção de dominação de Weber é que se trata de uma visão tão ampla que dá margens a uma variedade de interpretações e ambiguidades. Frank Lovett diz que, dentre outras lacunas, a concepção de dominação de Weber nos permite deduzir que "a classe de trabalhadores sob o modo de produção capitalista está sujeita a dominação pela ideologia liberal do laissez-faire que faz sua subordinação parecer justa e equitativa, quando de fato eles estão sendo explorados pelos capitalistas" (2010, p. 86). Por essa ótica, podemos tomar a dominação como uma realidade que acontece em qualquer cultura e sofre ligeiras variações com o tempo, sem margem para contestação por se tratar de relações de dominação baseadas em normas e costumes tradicionais.

Outras conotações que o termo dominação assume são encontradas na obra de Michel Foucault e Karl Marx que, guardadas as suas respectivas diferenças podem ser entendidas com o que Lovett classifica como uma concepção de dominação como "desequilíbrios de poder" (imbalance power). Na ótica de Foucault, o fenômeno da dominação preexiste ao estado e reside em todo tecido social e está esquadrinhado em todos os recantos da vida política, embora tenha seu caráter histórico e, portanto, esteja sujeito a transformações é algo estrutural.

As abordagens da dominação feita pelos autores supracitados não coincidem com a dominação dentro do republicanismo, embora eu esteja certo de que os diagnósticos de Marx sobre a exploração dos trabalhadores e a alienação tenham uma riqueza conceitual que nos permite integrá-los a teoria da dominação tratada dentro do republicanismo.

Em linhas gerais, Pettit defende a não dominação como uma teoria da liberdade e como heurística de uma teoria da justiça. Por dominação, o autor entende a condição de viver a mercê da vontade de terceiros que podem interferir de forma arbitrária em determinadas escolhas as quais não caberia ingerência. Segundo a teoria, para que se possa configurar uma relação de dominação não precisa a interferência ocorrer de fato, a própria condição de estar a depender da boa vontade de outrem já gera uma situação de dominação em virtude da insegurança gerada diante de uma interferência eminente. Ser livre requer ter recursos naturais, pessoais e sociais que permitam uma ação livre, de acordo com a vontade do agente, em outras palavras, a liberdade implica viver livre do domínio e da vontade de outros. O paradígma de dominação que serve como referência para a teoria republicana é o do senhor e do escravo onde o senhor exerce um tipo de controle que é intencional, consciente e de certo modo coercitivo, uma vez que, para realizar determinadas escolhas a pessoa dominada precisaria da anuência do dominador.

Embora a dominação possa assumir distintas facetas, creio que seja possível deduzir dois aspectos essenciais desse conceito dentro da tradição republicana. De um lado, existe a dominação de indivíduos ou grupos que podem usar recursos diversos para dominar outrem, os recursos que permitem que determinado agente estabeleça uma relação de dominação variam bastante: vigor físico, poder econômico, status social dentre outros. Essas formas de dominação resultam das relações dos indivíduos entre si 
e entre a comunidade. Uma segunda forma de dominação se dá pela ordem política na figura do estado e suas respectivas instituições.

Pettit classificou essas duas formas de dominação de dominium e imperium, respectivamente. Note que a primeira forma de dominação, dominium, é resultado das relações que os indivíduos estabelecem entre si. O dominium está susceptível de ocorrer, por exemplo, numa relação marital, na relação patrão empregado, na relação dos pais com as crianças dentre outras situações onde há indivíduos numa situação que lhe permita dominar outrem em virtude de algum poder ou autoridade, esta forma de dominação pode ser resolvida recorrendo-se ao estado através de suas instituições pensadas para resolver esse tipo de demanda. Já segunda faceta da dominação, chamada de imperium, acorre em virtude dos aparatos institucionais que foram criados para coibir a primeira forma de dominação. Enquanto a primeira diz respeito às relações horizontais dos indivíduos entre si, a segunda considera a relação vertical do estado com os cidadãos, esta forma de dominação se dá, portanto, quando há uma disfunção do estado que, ao invés de ser uma instância de equalização das relações de dominação converte-se numa forma de dominação muito mais poderosa que a dominação presente no interior da sociedade civil. A seguir abordei com mais detalhe estas duas faces da dominação.

\section{DOIS ASPECTOS DA DOMINAÇ̃̃o}

\section{Dominium}

O fenômeno da dominação mais visível se dá através da subordinação ou controle de um agente sobre outrem. Este tipo de dominação está na origem de qualquer relação humana sem regulação. Evidentemente que nem toda relação hierárquica de poder deve ser caracterizada como dominação na acepção que tomamos aqui. A forma de dominação mais primitiva que podemos presumir talvez seja aquela resultante da vantagem física que determinados agentes possuem sobre outros. É claro que as possibilidades de dominação não são redutíveis às vantagens físicas, com a complexidade das formas de socialização ganhou força a dominação pelo uso do poder econômico, pela aquisição de conhecimento e habilidades, se estendendo para uma amplo leque de mecanismos inerentes a relação hierárquica-estrutural.

Partindo dos pressupostos que subjazem as teorias da justiça contemporâneas, segundo os quais os recursos são limitados, podemos deduzir consoante o pensamento de Maquiavel que os agentes que dispõem de mais recursos que os outros tendem a estabelecer uma relação de dominação. Dessa forma, a fórmula "dominação como interferência arbitrária" deve ser pensada não como mera interferência na ação, mas também, e, sobretudo, como posse de meios que possibilitem a obtenção de vantagens em benefício pessoal ou privado, a aquisição de saberes e competências, por exemplo, podem resultar numa forma de dominação na medida em que determinados agentes podem usar tais habilidades para enganar, ludibriar e obter vantagens. Estes benefícios obtidos através das estruturas hierárquicas fazem com que alguns estejam numa posição que lhes permitam ter controle sobre aqueles estão em uma escala hierárquica inferior a 
sua.

Existem, todavia, algumas divergências sobre o conceito de dominação dentro do republicanismo. Machael J. Tompson, por exemplo, faz uma leitura mais radical, ampliando o alcance da dominação para outras esferas. Enquanto Pettit acredita que a dominação em forma de dominium pode ser resolvida, recorrendo-se ao direito, Thompson vê falhas e vícios nas normas jurídicas e aponta para os imperativos burocráticos que predominam nas economias de mercado capitalistas onde os trabalhadores são explorados com a legitimidade das normas ou pela ausência destas. Segundo Thompson: "Quando os ricos são capazes de desfrutar de tempo livre ou outros luxos, eles são capazes de fazer isso por consumir o trabalho e os esforços de outras pessoas: motoristas, empregadas domésticas, cozinheiros, e assim por diante." (2015, p.6) Esta concepção de dominação de Thompson traz uma ligeira correspondência com a visão de Maquiavel para quem a dominação está amarrada ao poder econômico. Nesse sentido, a dominação estaria ligada a apropriação de recursos produzidos por outras pessoas, ainda que de forma legal. Irei argumentar, contudo, que embora esta descrição da dominação esteja correta, isto requer um tipo diferente de análise da dominação e do poder social. O dominium, descrito acima, corresponde a um tipo de corrupção que permeia a sociedade civil e está materializado no uso de posições de poder para poder obter benefícios próprios em detrimento dos objetivos da comunidade como um todo; na subjugação daqueles que estão numa escala de poder inferior; na obtenção de vantagens pessoais indevidas em virtude do cargo que se ocupa e assim por diante. Embora a linha que divida a dominação institucionalizada pelas normas, chamada aqui de imperium e a dominação oriunda da corrupção e da usurpação, descrita acima como dominium, seja uma linha muito tênue, esta divisão se faz necessária por se tratar de duas escalas de dominação. Se o dominium tem sua fundamentação em Maquiavel que centrou sua crítica na usurpação e dominação dos ricos sobre a plebe, o imperium guarda uma ligeira referência a Rousseau que deteve sua crítica à autoridade, mais especificamente Rousseau criticou a autoridade natural ou religiosa que impunha ordens como forma de dominação.

\section{Imperium}

O estado que é uma instituição para garantir a liberdade pode, na contramão de sua função originária, se converter numa estrutura corrosiva a liberdade no interior da república, seja através de políticas de governo, seja por abusos por parte do judiciário para quem sobra certa margem de discricionariedade, seja por parte do legislativo que pode caminhar no sentido de cercear os direitos conquistados pelas minorias, por exemplo. Assim, a grande preocupação da teoria a republica passa a ser a vigilância dos cidadãos para que o estado através de suas instituições não se converta numa instância de dominação:

Não há motivo para criar instituições ou para tomar iniciativas que reduzam a dominação associada ao dominium se esses mesmos instrumentos dão lugar para o tipo de dominação associada ao imperium; o que se ganha por um lado será perdido - e talvez mais que perdido - por outro lado. (Pettit, p.173) 
A criação de um estado forte, com mais poder de coerção e mais rigor na aplicação das normas poderia trazer ainda mais prejuízos para a efetivação da liberdade. Se reduzirmos a liberdade ao seu aspecto jurídico poderíamos deduzir que em uma ditadura ou em um estado despótico qualquer somos livres. Mesmo em um regime democrático não estamos imunes à dominação em virtudes das várias possibilidades de interesses corporativos, lobbys e acordos de barganha ser moldados à revelia dos interesses comuns, do bem público e das funções da república. Nesse sentido, talvez se possa abduzir que a justeza de um estado pode ser balizada pela sua capacidade de ajustar seus rumos com a promoção da não dominação. Isto requer pensar a dominação como um bem comum, como um ideal político de justiça que o estado deve perscrutar tanto pelo viés procedimental como por política de governo.

\section{UMA TERCEIRA FACETA dA dOMinaÇão IGNORAdA POR PETTIT}

Há outro aspecto da dominação que não é contemplada na teoria da dominação de Pettit, mas que pode ser vislumbrado se ampliarmos o alcance da crítica republicana as relações de dominação. Thompson chamou essa forma de dominação de "dominação constitutiva". Trata-se de uma forma de dominação cujos pressupostos estão dados na teoria social e na pesquisa sociológica. A esta terceira forma de dominação, a qual doravante eu tomarei de empréstimo a designação de Thompson de dominação constitutiva, se refere à dominação no âmbito dos valores, da cultura e da consciência coletiva. Está na possibilidade de se forjar relações de dominação como sendo legítima e reproduzi-las em todos os âmbitos da vida social. É uma das nuances da dominação que está, por exemplo, na exploração do trabalhador, nas relações de gênero e outras formas de dominação que ocorrem com a anuência do dominado e legitimados pela cultura.

A dominação constitutiva encontra-se disseminada nas nossas instituições e é legitimada pelas práticas cotidianas que a reproduz em todos os espaços de socialização. Corroborando com o que Clarissa Hayward argumentara "É, acima de tudo, não só a força exercida por outros agentes humanos, mas também a força exercida por hábitos profundamente enraizados, por tradições não examinadas, e pela rotinização excessiva" (p. 484). Enquanto o dominium constitui uma forma de dominação que pode se recorrer ao estado através de suas instituições e o imperium resulta de uma dominação levada a cabo por uma disfunção do estado, a dominação constitutiva por seu turno é operacionalizada no âmbito da vida civil e referendada pelos aparelhos do estado. Se pensarmos, por exemplo, nas relações patrão-empregado podemos notar que a história das injustiças e da dominação vai se reproduzindo sem que haja problemas com o cumprimento da lei. Da mesma forma, se formos para outros campos como os papeis de gênero que tendem a reproduzir as normas e obedecer às leis perceberemos que há uma obediência tácita e talvez com tendências a naturalização dos comportamentos. Como bem argumentou Thompson a esse respeito:

É um tipo de dominação porque é capaz de controlar o indivíduo de dentro, moldar dimensões cognitivas, assim como dimensões avaliativas da consciência e da personalidade para aceitar certas relações sociais como legítimas, especialmente quando elas não estão nos interesses objetivos dos próprios indivíduos. $(2015$, p. 7$)$ 
Ou seja, a dominação pode ocorrer no processo de formação da opinião e da vontade, forjando a consciência. É um processo cultural que é mais difícil de resistir do que qualquer outra forma de dominação. Conforme Thompson, podemos dizer que a dominação constitutiva é um poder de: (i) influenciar as normas sociais, (ii) roteirizar os valores para se manter os padrões de dominação (iii) moldar a consciência, orientar as competências cognitivas e avaliativas (iv) legitimar o dominium.

Esta última característica se dá porque as normas tem a capacidade de socializar agentes. A segundo faceta da dominação, conforme ressaltou Thompson, resulta de

\begin{abstract}
Um poder ou capacidade de moldar as formas de autoridade legítima através das normas e dos valores que orientam as suas ideias sobre o mundo social e a lógica das instituições que você está inserido e que socializa você. Esta ideia de dominação é uma característica essencial de qualquer sociedade organizada hierarquicamente em que as relações de poder são verticalmente distribuídas e há alguma forma de desigualdade social - de recursos, riqueza, prestígio, etc. (2015, p. 2)
\end{abstract}

Esse aspecto da dominação nos remete a alguns pressupostos do Marxismo e da teoria crítica, embora a dominação constitutiva não faça referência direta ao conceito de ideologia como um sistema de ideias sustentadas por um grupo social, as quais refletem, racionalizam e defendem os próprios interesses e compromissos institucionais, sejam estes morais, religiosos, políticos ou econômicos (Cf. Houaiss, 2001) Contudo, com a dominação constitutiva nós nos deparamos com o resultado de um processo de inculcar valores e forjar a consciência, isto é, vai além do processo de falsear a realidade.

Se tomarmos o conceito de ideologia de Marx, o conceito de dominação de Weber, o conceito de ontologia social de Searle ou mesmo a noção de socialização de Parson, esteremos no caminho certo para adentrarmos ao conceito de "dominação constitutiva." Isso não significa, no entanto, que não tenhamos nenhum parâmetro moral para pensar a legitimidade do direito, por exemplo, mas apenas que esses parâmetros são construtos sociais forjados para criar e manter as formas de dominação.

No ponto seguinte, eu gostaria avaliar o modelo de crítica social apresentado pela teoria crítica de Honneth através de seu método de reconstrução normativa com a finalidade de discutir se a proposta teórica de Honneth serve para identificarmos as patologias sociais e se é possível deduzir do método de reconstrução normativa de Honneth as bases para uma teoria da justiça adequada. Considerarei a reconstrução normativa de Honneth adequada na proporção em que ela for capaz identificar através de seu método as formas de dominação social e que possa apresentar um potencial emancipatório.

A reconstrução normativa da liberdade: potencialidades e déficits

"O povo desejava gozar as supremas honras juntamente com os nobres" (Maquiavel, 1993c, p.690).

No contexto em Maquiavel fala das reivindicações da plebe, o reconhecimento estava atrelado as posições de poder que se ocupava numa determinada hierarquia. Respeitavam-se aqueles que pertenciam à nobreza e ocupavam determinadas funções no quadro social. Contudo, na medida em que foi surgindo as sociedades democráticas, o reconhecimento, antes restrito aos membros da nobreza, foi entrando em colapso e dando lugar a noção de igual dignidade. Agora, o povo quer ser reconhecido naquilo 
que ele é, ou seja, o desejo do povo é de gozar das mesmas horarias, usufruir do mesmo status dos demais membros da sociedade, ainda que não tenha origem ou vínculos com a nobreza. Segundo Charles Taylor, essa mudança de paradigma se deu acompanhada do ideal de identidade individual, isto é, de um ideal de autenticidade, fundada no pressuposto que cada indivíduo é original e único. Pensadores modernos como Rousseau, Kant e Fichte levaram a cabo a ideia da prioridade da autonomia e da autenticidade do indivíduo no sentido de fundamentar uma concepção autorreferencial da liberdade do indivíduo.

Em certa mediada, o projeto de Honneth se inscreve nesta tradição de pensamento que tem por objeto a liberdade centrada na autonomia individual do sujeito, sem conduto reduzi-la ao seu aspecto autorreferencial individualizante. Em seu livro $O$ direito da Liberdade (2015), o autor se propõe a: i) superar o caráter individualizante de sua teoria do reconhecimento; ii) formular uma política normativa que supere o hiato entre teoria e práxis. $\mathrm{O}$ autor para dar cargo desse intento segue dois passos: a) assume liberdade como valor central nas sociedades atuais e usando o que ele chama de modelo teórico-metodológico de reconstrução normativa procura identificar como as sociedades democráticas vem definindo a liberdade, essa abordagem histórico-normativa da liberdade permite ao autor detectar patologias em duas concepções de liberdade que tem prevalecido da antiguidade até a modernidade: a liberdade negativa (liberdade jurídica) e a liberdade positiva (liberdade moral).

Faz parte de sua reconstrução normativa a superação da dicotomia liberdade negativa versus liberdade positiva (reflexiva) que corresponde, respectivamente, à liberdade dos antigos e a liberdade dos modernos. Os motivos pelos quais Honneth rejeita estas duas perspectivas da liberdade é bem parecido com os fundamentos que levaram o republicanismo de Pettit a fugir da referida dicotomia, contudo, enquanto o republicanismo está mais próximo da liberdade negativa, uma vez que a fórmula "liberdade como não dominação" requer inicialmente a proteção jurídica da liberdade que posteriormente será efetivada mediante a participação cívica ativa numa forma de democracia contestatória. Honneth, por seu turno, não pensa a liberdade como um bem ameaçado pelas relações de dominação, mas como um bem a ser atingido por meios das relações de reconhecimentos recíprocos. Assim, enquanto Pettit vislumbrou as ameaças reais e potenciais a liberdade, Honneth vislumbrou as condições e possiblidades de autorrealização individual presentes na sociedade.

Em comum talvez tenhamos que ressaltar que ambos os autores evitam deduzir uma concepção de liberdade a partir de princípios apriorísticos transcendentais. Partindo de uma leitura de Hegel, Honneth afirma que estrutura conceitual autorreferente da liberdade individual sintetizada na fórmula "estar junto a si mesmo no seu outro", e que se exprime no direito e na moralidade, necessitando ser reelaborada nas diversas instâncias da intersubjetividade social - esferas necessárias da autorrealização - desde a família, passando pela sociedade civil e desembocando na esfera política do Estado, nas quais as relações comunicativas possibilitam ao indivíduo estar consigo mesmo no seu outro. Assim, em virtude desse caráter intersubjetivo da liberdade, o reconhecimento passa a ser uma categoria central, porque o sujeito precisa reconhecer na liberdade do outro a sua própria liberdade. A liberdade, dessa forma, tem seu aspecto subjetivo (estar consigo mesmo) e objetivo (no seu outro), materializado nas instituições que a reconhece. 
O desafio a qual Honneth se propõe em seu novo livro é extrair uma concepção de justiça do âmbito da vida social, que Hegel chamou, à sua época, de eticidade (Sittlichkeit). Isso implica buscar, dentro da própria estrutural social já existente, os fundamentos da justiça. Embora tal intento corra o risco (e o autor é consciente de tais riscos) de "conservar nas sociedades somente as práticas e disposições morais que pareciam talhadas para conservar a ordem dominante". (Honneth 2015, p. 27). Diante dessa possibilidade de uma deterioração de comportamentos, que pode se tornar aquilo que na linguagem do republicanismo se chama de "instancias de dominação," Honneth recomenda a passagem da reconstrução normativa para a crítica reconstrutiva, quando o desafio é fazer uma crítica às "patologias sociais", utilizando-se da própria eticidade e padrões morais para denunciar uma insuficiente ou incompleta encarnação de valores geralmente aceitos. Nesse contexto, talvez seja o caso se falar em patologia social que corresponde a "uma notável deterioração das capacidades racionais de membros da sociedade ao participar da cooperação social de maneira competente" (2015, p. 157) As patologias não se expressam em estados psíquicos doentes, como se poderia pensar, o estado patológico, nas palavras do autor, está naquele que "desaprendeu, por força de influências sociais, a praticar adequadamente a gramática normativa de um sistema de ação intuitivamente familiar (p.158). Contudo, não estão muito claros, no decorrer de sua obra, os indícios de quando se deve passar da reconstrução normativa para a crítica reconstrutiva. Ou seja, em termos de diagnóstico das patologias das sociedades atuais, o autor não tem a mesma contundência e potencial crítico que tiveram os autores da primeira geração da teoria crítica. A esse respeito, o autor afirma que a pesquisa sociológica é por demais grosseira para trazer esse tipo de prognóstico, por isso, atesta que "a via mais eficaz para um diagnóstico patológico continua a ser, e assim já era nos tempos de Hegel e do jovem Luckács, as análises de testemunhos estéticos, nos quais o referidos sintomas chegam a receber uma apresentação indireta" (p. 159). Os filmes, romances dentre outras formas de arte podem fornecer material para pensar as deformidades de comportamento, bem como seu grau de alastramento.

Como chave para seu processo de reconstrução normativa, Honneth identifica a liberdade como valor central no qual está subsumida a multiplicidade de valores particulares das democracias liberais. Essa premissa, segundo o autor, tem apoio numa longa tradição filosófica que vem de Hegel, passando por Durkheim, até Habermas e Rawls. Assim, toda a reconstrução histórico-normativa tem a liberdade como fio condutor. Então, o autor procura identificar as patologias da liberdade negativa e da liberdade positiva. Segundo o autor, a liberdade negativa (às vezes também caracterizada como liberdade jurídica) é deficiente porque nos remete a uma concepção atomizada do sujeito sem espaço para mediação social ou para o gozo intersubjetivo da liberdade. Ou seja, a liberdade jurídica não deixa espaço para a reflexividade. Já a liberdade reflexiva (moral) tem um avanço, uma vez comparada a liberdade negativa porque não se pauta apenas no cumprimento da norma jurídica, o seu caráter reflexivo demanda a justificação das normas de ação a serem observadas por todos. Enquanto a liberdade jurídica nos remete a Hobbes, a liberdade moral tem em Kant o sua sustentação. O seu caráter reflexivo está ancorado na ideia de esclarecimento que pressupõe um sujeito autônomo, que supere a heteronomia e seja autolegislador.

Apesar dos avanços da liberdade reflexiva de Kant, trata-se de um modelo que ainda tem suas patologias por pressupor um sujeito autorreferente que siga leis 
autoprescritas. Honneth já fizera essa crítica em Sofrimento de indeterminação (2007), em referência às indeterminações da moral kantiana. As patologias da liberdade moral estão no indivíduo que não insere seu agir num contexto de vida ético; está no ponto de vista do desinteressado e do imparcial que "é livre de todos os seus deveres associados a seus respectivos papeis, a ponto de conduzir seu agir única e exclusivamente pelo fio condutor de sua universalidade"(2015, p.210). Essas patologias estão tipificadas na "personalidade do moralista desvinculado" como no seu oposto: "o terrorista fundamentado na moral" (p.210).

Em virtude das duas visões da liberdade descritas anteriormente se apresentarem como patológicas, Honneth irá propor a liberdade social com caráter profilático com vistas a curar as patologias descritas. Enquanto as duas visões anteriores apresentam-se ao indivíduo a possibilidade do agir moral baseado apenas em suas motivações particulares; sem prestar contas do seu agir ou reduzindo seu papel ao aspecto jurídico; a liberdade social só se completa na mediação com outro. $\mathrm{O}$ autor se baseia numa ideia de que as instituições sociais "permitem aos sujeitos se relacionarem uns com os outros, já que eles poderiam compreender sua contraparte como outro de si mesmos." (p.85) Nesse caso, a aspiração da liberdade deixa de ser uma expectativa subjetiva já que visa encontrar nos demais sujeitos um reconhecimento si.

\section{CONSIDERAÇÕES FINAIS}

Honneth tem duas contribuições a dar para teoria republicana. Primeiro ao colocar o reconhecimento como categoria mediadora para uma teoria da liberdade; segundo pela abordagem da dimensão produtiva dos conflitos sociais com o epicentro nas lutas por reconhecimento. Contudo, estes dois aspectos aparecem muito pouco no último livro de Honneth, $O$ direito da liberdade. Talvez tenha faltado ao filósofo de Frankfurt uma conexão mais direta com seus primeiros trabalhos, especialmente The Critique of Power (1991) e Luta por reconhecimento (2003). Emil Sobottka (2014) comunga dessa intuição ao ressaltar que "Surpreende também que o reconhecimento seja tematizado em todo o livro como uma relação bastante pacífica, deslocando da análise a dimensão produtiva do conflito social, antes o centro de gravidade da teoria do reconhecimento." (p.223).

Do republicanismo Honneth talvez tenha que assimilar que na equação do reconhecimento a não dominação precisa ser conjugada porque para que se obtenha um reconhecimento completo as relações intersubjetivas ensejam a recusa de quaisquer tipos de dominação, do contrario, a teoria do reconhecimento de Honneth retroage aos mesmos erros da teoria hegeliana que presumia uma relação de reconhecimento na dialética do senhor e do escravo, ou seja, é possível que se obtenha reconhecimento numa relação de dominação, mesmo que seja uma forma muito primitiva de reconhecimento. Há, portanto, uma relação de complementariedade entre o desejo de reconhecimento e o desafio de se proteger e ao mesmo tempo fomentar uma cultura política que minimize as relações de dominação. Do ponto de vista das instituições políticas

\section{REFERÊNCIAS}


HAYWARD, Clarissa Rile. What can political freedom mean in a multicultural democracy? On deliberation, difference, and democratic governance. Political Theory, p. $0090591711408245,2011$.

HEGEL, Georg Wilhelm Friedrich. Linhas fundamentais da filosofia do direito, ou direito natural e ciência do Estado em compêndio. Trad. Paulo Meneses [et. al.]. São Leopoldo, RS: Ed. UNISINOS, 2010.

HONNETH, Axel. Luta por reconhecimento: a gramática social dos conflitos sociais. São Paulo: Editora 34, 2003. O direito da liberdade. Trad. Saulo Krieger. - São Paulo: Martins Fontes, 2015. . Sofrimento de indeterminação: uma reatualização da Filosofia do direito de Hegel. São Paulo: Esfera Pública, 2007

. The critique of power: reflective stages in a critical social theory. Trad: Kenneth Baynes - 1st MIT Press ed. 1991.

LOVETT, Frank. A general theory of domination and justice. Oxford University Press, 2010

McCORMICK, John. Machiavellian democracy. Cambridge, Cambridge University

Press, 2011.

PETTIT, Philip. 2012. On the people's term: a republican theory and model of democracy. Cambridge: Cambridge University Press.

Republicanism: a theory of freedom and government. Oxford: Oxford University Press, 1997.

SOBOTTKA, Emil A. A liberdade institucional e suas expressões institucionais. Revista Brasileira de Ciências Sociais, v. 27, nº 80, p. 219-223.

TAYLOR, Charles. La etica de la autenticidad. Barcelona: Ediciones Paidós, 1994.

THOMPSON, Michael J. The two faces of domination in republican political theory. European Journal of Political Theory, p. 1474885115580352, 2015. . The Domestication of Critical Theory. 2016. 